\title{
Serum Amyloid A
}

\section{EVIDENCE FOR ITS ORIGIN IN POLYMORPHONUCLEAR LEUKOCYTES}

\author{
C. Julian Rosenthal and Lee Sullivan, Division of Hematology-Oncology, \\ Department of Medicine, Downstate Medical Center, State University of \\ New York, Brooklyn, New York 11203
}

A B S T R A C T In this study the presence of an amyloid $A$, antigenically related material was determined in four subpopulations of human leukocytes. Monocytes, granulocytes, thymus-derived lymphocytes, and bone marrow-derived and null lymphocytes were isolated from the peripheral blood of five apparently normal subjects, two patients with secondary amyloidosis, three patients with acute infections, and seven patients with metastatic cancer. Mononuclear leukocytes, isolated from the interface of a Ficoll-Hypaque gradient, were separated into monocytes, thymus-derived lymphocytes, and bone marrow-derived plus null lymphocytes by glass adherence and depletion of sheep erythrocyte rosette-forming lymphocytes. Granulocytes were isolated by sedimentation in $2 \%$ methyl cellulose from the erythrocyte-rich pellet formed at the bottom of the Ficoll-Hypaque gradient. The four isolated leukocyte subpopulations were cultured and, at varying intervals, the amyloid A content of the culture medium and of sonicated, $2 \times 10^{6}$ cells was determined by radioimmunoassay. Our results indicated a 2-14 times greater amount of amyloid A-related material in the sonicated granulocytes compared with the individuals' serum amyloid A levels. The mononuclear subpopulations showed a low or negligible amyloid A content. The amount of amyloid $A$ antigenic material was further found to increase in cultured granulocytes, reaching a peak value between the 16th and 30th $h$ of culture. The granulocytes of only two out of eight individuals tested released amyloid A antigenically related material into the culture medium. This release was found to be blocked by the presence of colchicine, vincristine, puromycin, or cycloheximide in the culture medium. In contrast, only the presence of puromycin or cycloheximide was shown to significantly inhibit the intra-

The data reported in this paper were presented in part at the 20th Annual Meeting of the American Society of Hematology in San Diego, Calif., December 1977.

Received for publication 18 May 1978 and in revised form 11 August 1978. cellular increase of amyloid $A$ in the cultured granulocytes. Thus, it appears that among the circulating blood cells, the granulocytes produce amyloid A antigenically related material and could release it under conditions that remain to be further defined.

\section{INTRODUCTION}

Despite recent progress in understanding the intricate nature of amyloid, very little is known about the origin of the amyloid A (AA) ${ }^{1}$ protein, one of the two major components of the amyloid fibrils (1), which is mainly found in patients with secondary amyloidosis and amyloidosis associated with familial mediterranean fever. Using an antibody produced against the alkalidegraded AA protein, an antigenically related component, serum amyloid A, (SAA) has been detected in human serum $(2,3)$ and a subunit of this component has been isolated and characterized (4-6). With the use of a radioimmunoassay (7), SAA has been found to be elevated in patients with chronic and acute inflammatory processes as well as in many cases of metastatic neoplastic disease (3, 7-9). These data, as well as those generated by studies on experimental amyloidosis in mammals $(10,11)$, have suggested that SAA might be produced by reticuloendothelial cells (11-13). However, recent studies by Watanabe et al. (14) have shown that AA antigenically related material is found in plasma cells and in the Kupfer cells of the liver. Linder et al. (15) have also demonstrated the presence of SAA antigenically related material in the loose connection tissue of human fetuses and in human fetal fibroblasts as part of the 10-nm intermediate size filaments of the cytoplasmic cytoskeleton. These data cannot satisfactorily explain the variations of the SAA level in some pathologic conditions (16). Furthermore, previous observations have indicated that bone marrow-derived (B)

${ }^{1}$ Abbreviations used in this paper: AA, amyloid A; PMN, polymorphonuclear; PMN AA, PMN AA antigenic material; SAA, serum AA. 
lymphocyte abnormalities play an important role in the formation of casein-induced amyloid (17). In view of these findings we attempted to determine the presence of AA antigenically related material in various cell populations isolated from human blood and to establish its variations in short-term cultures of the same populations. Herein we report evidence that polymorphonuclear leukocytes are the only peripheral blood cells that contain significant amounts of this material and most likely produce and release it in the serum.

\section{METHODS}

Determinations of the SAA content of various subpopulations of circulating leukocytes. Four subpopulations of leukocytes-thymus-derived (T) lymphocytes, B and null lymphocytes, monocytes, and polymorphonuclear (PMN) leukocytes-were isolated from $60 \mathrm{ml}$ of heparinized blood from five normal individuals, ages $25-40 \mathrm{yr}$ and 12 patients with high SAA levels. Among these 12 patients, 2 suffered from chronic inflammatory disorders and secondary amyloidosis, 7 had metastatic neoplasia, and the remaining 3 had acute inflammatory processes. The blood was applied to a FicollHypaque gradient (Ficoll, Pharmacia Fine Chemicals, Piscataway, N. J.; Hypaque, Winthrop Laboratories, Sterling Drug, Inc., New York) (18) and centrifuged to yield a mononuclear cell population at the interface and a PMN and erythrocyte-rich population at the bottom. PMN leukocytes were then separated from the erythrocyte population by sedimentation in $2 \%$ methyl cellulose and alpha medium (Flow Lab. Limited, Irvine, Ayrshire, Scotland). The monocytes were first separated from the isolated mononuclear cells by adherence to the wall of polystyrene sterile flasks. After $1 \mathrm{~h}$ incubation at $37^{\circ} \mathrm{C}$, the nonadherent lymphocytes were discarded and the monocytes detached from the flask with a rubber policeman (19). The nonadherent $T$ lymphocytes were separated from B and null lymphocytes in another FicollHypaque gradient after formation of $T$ sheep erythrocyte rosettes $(20)$. All the peripheral blood cell subpopulations thus separated were thoroughly washed and then suspended in $0.15 \mathrm{M}$ phosphate-buffered saline ( $\mathrm{pH} 7.2$ ) at the concentration of $2 \times 10^{6} \mathrm{cells} / \mathrm{ml}$. The leukocytes were tested for viability by the trypan blue exclusion technique and used for further studies only if viable cells amounted to $>95 \%$. The cells, in $10 \times 75-\mathrm{mm}$ tubes, were subsequently disrupted by sonication for 2 min with a Branson sonicator (Heat Systems-Ultrasonics, Inc., Plainview, N. Y.). The amount of AA-related antigen, contained in the suspensions of various sonicated leukocyte subpopulations and in the corresponding serum of the individuals studied, was determined by a radioimmunoassay technique previously reported in detail (7). The results are expressed in nanograms per milliliter of AA-equivalent antigen.

To assess the possible distortion of these results as a result of binding of circulating SAA to some of the leukocyte subpopulations, we also determined their ability to bind in vitro pure SAA obtained (6) from two patients with secondary amyloidosis.

Kinetics of the SAA content of various leukocyte subpopulations in culture and those of its release. Cultures were established with each of the separated leukocyte subpopulations from six different patients with elevated SAA levels and two normal individuals. After appropriate washing in $0.15 \mathrm{M}$ phosphate-buffered saline, $2 \times 10^{6} \mathrm{~B}$ or T lymphocytes were suspended in $2 \mathrm{ml}$ RPMI 1640 medium with $15 \%$ fetal calf serum and antibiotics (100 $\mu \mathrm{m}$ of penicillin and $50 \mu \mathrm{g}$ of streptomycin per $\mathrm{ml}$ ) and cultured in sterile plastic tubes (Falcon Plastics, Div. of BioRad, Oxnard, Calif.) at $37^{\circ} \mathrm{C}$ in a $5 \% \mathrm{CO}_{2}$ atmosphere. The monocytes adherent to the wall of polystyrene $25-\mathrm{ml}$ sterile plastic flasks were maintained in culture with $10 \mathrm{ml}$ of identical medium for $10 \times 10^{6}$ adherent cells. PMN leukocytes were incubated in a medium (McCoy 5A, RPMI 1640, or 199 [Grand Island Biological Co., Grand Island, N. Y.] with $15 \%$ fetal calf serum and antibiotics) at a cell concentration of $2 \times 10^{6}$ per $2 \mathrm{ml}$ of medium per tube and maintained in a $7.5 \% \mathrm{CO}_{2}$ atmosphere. The cultures were interrupted at various time intervals, usually every $4 \mathrm{~h}$, for $72 \mathrm{~h}$ for the PMN leukocytes and every $12 \mathrm{~h}$ for 7 days for the monocyte and lymphocyte subpopulations. The amount of antigenically related AA protein in the supernate and in the sonicated-cell pellet of each cell population as well as in appropriate controls, was determined in triplicates at each time interval.

The AA content of sonicated PMN leukocytes and their supernates, obtained from eight subjects, was also determined after adding to separate culture tubes the protein synthesis inhibitors, puromycin (Sigma Chemical Co., St. Louis, Mo.), $0.1 \mu \mathrm{g} / \mathrm{ml}$, or cycloheximide (Sigma Chemical Co.), $10 \mu \mathrm{g} / \mathrm{ml}$, as well as $0.2 \mu \mathrm{g} / \mathrm{ml}$ of vincristine (Eli Lilly \& Co., Indianapolis, Ind.), vinblastine (Eli Lilly \& Co.), or colchicine (Eli Lilly \& Co.), known antitubulin agents. The concentration of these various substances was chosen after preliminary experiments had established for each agent the concentration causing maximal decrease of the intracellular AA level without increased cytotoxicity.

\section{RESULTS}

SAA content of leukocyte subpopulations. The PMN leukocytes, from all patients and normal individuals tested, contained a significant amount of AA antigenically related material as shown on Fig. 1. The AA content of the PMN leukocytes correlated with the level of SAA in the corresponding sera. The ratio between PMN AA antigenic material (PMN AA) and SAA varied between 2 and 14 with a mean of 6 . The amount of PMN AA was found to vary in direct proportion with that of the SAA (Table I). These parameters were determined sequentially before, during, and after an acute inflammatory process as well as in patients with partial short-lasting remissions of disseminated neoplastic disease. On a few occasions in which AA was found in lymphocytes and monocytes, in a concentration above the minimal level discernible by radioimmunoassay $(40 \mathrm{ng} / \mathrm{ml})$, the ratio of lymphocyte AA antigenic material or monocyte AA antigenic material over SAA was significantly under one. One exception of note was the monocyte population of a patient (GN) with metastatic carcinoma of the lung and chronic osteoarthritis, which contained an amount of AA antigenically related material equal to that of his PMN leukocytes (Fig. 1). However, this discordant result could be explained by the presence of $24 \%$ bands (young PMN leukocytes) among the patient's peripheral leukocytes which separated in the Ficoll-Hypaque gradient with the monocyte subpopulation. 


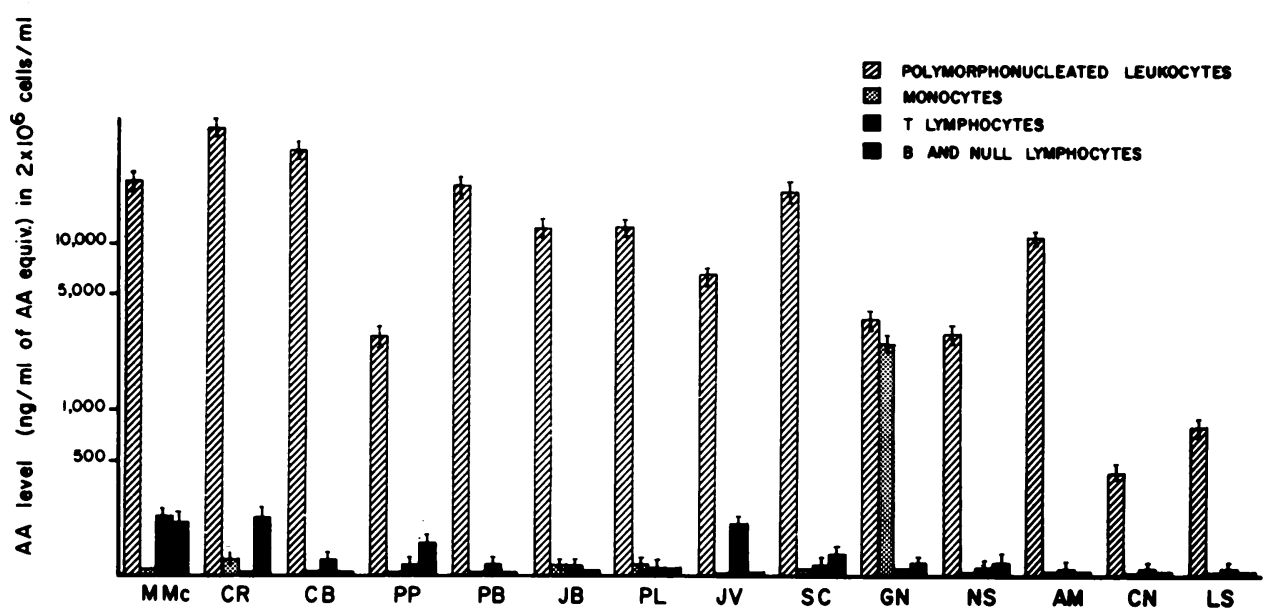

FIGURE 1 AA antigenically related material in various leukocyte subpopulations. Each group of bars represents the levels of cell subpopulations from the same individual marked by initials along the abscissa. The first 12 groups of results are from patients with moderate or high SAA levels. The last two groups belong to two of the five normal subjects tested who had normal SAA levels (the results of the other three normal individuals not depicted on the graph had the identical pattern and proportions as the ones presented).

To establish the validity of the previous results it was necessary to eliminate the possibility that the increased level of AA-related material after the disruption of PMN leukocytes may have been an artifact caused by the interference of active leukocytic enzymes with the formation of the antigen antibody complex in the radioimmunoassay. For this purpose the AA level of the sonicated granulocyte suspensions was determined before and after their boiling for $10 \mathrm{~min}$ at $100^{\circ} \mathrm{C}$, because it has previously been reported, by us (7) and others $(3,4)$, that the AA protein is not degraded by boiling, whereas most of the leukocytic enzymes are inactivated at $100^{\circ} \mathrm{C}$. The high levels of $\mathrm{AA}$ antigenically related material of the sonicated PMN leukocyte suspensions remained unchanged after boiling. Binding experiments were then performed to eliminate the possibility that high PMN AA levels may have been caused by tight binding of circulating SAA to PMN leukocytes (Table II). These experiments showed that only $\mathrm{T}$ lymphocytes and monocytes consistently retained radioactive material, having two to three times more counts per minute than the inert latex particles used as control. The PMN leukocyte pellet gave radioactivity counts equal to that of the control latex particles. The percentage of radioactivity retained by the PMN leukocyte pellets was found to be the same $(\cong 5 \%)$ irrespective of the SAA level of the subjects from whom granulocytes were obtained (Table II). Also when, in the in vitro binding experiments, we added an amount of cold SAA 10 times greater than that of the radioactive SAA, the percentage of radioactivity retained by the cell pellet of $\mathrm{T}$ lymphocytes and monocytes had decreased to $\cong 5 \%$, whereas no change was noted in the percentage of radioactivity retained by PMN leukocytes and by B

TABLE I

SAA-PMN AA Interrelation

\begin{tabular}{lcrrrrrrrr}
\hline Subjects & PMN AA & SAA & $R^{*}$ & PMN AA & SAA & R & PMN AA & SAA & R \\
\hline \multicolumn{7}{c}{$n$ ng/ml AA eq } \\
CB & 8,250 & 2,500 & 3.3 & 1,670 & 465 & $3.6(14)$ & 1,300 & 420 & $3.1(35)$ \\
MD & 3,600 & 500 & 7.2 & 1,900 & 275 & $6.9(21)$ & 3,200 & 425 & $7.5(49)$ \\
CC & 4,750 & 950 & 5.0 & 6,075 & 1,350 & $4.5(21)$ & 4,475 & 860 & $5.2(49)$ \\
CL & 1,625 & 650 & 2.5 & 5,250 & 2,500 & $2.1(21)$ & 900 & 310 & $2.9(42)$ \\
PT & 6,300 & 1,500 & 4.2 & 2,750 & 650 & $4.2(14)$ & 12,250 & 2,500 & $4.9(15)$ \\
\hline
\end{tabular}

The numbers in parentheses indicate for each patient the number of days between the first and subsequent determinations of SAA and PMN AA. CB and MD are patients with intermittently active rheumatoid arthritis; CC, CL, and PT are patients with disseminated neoplastic disease who had short-lasting, partial remissions.

* $\mathrm{R}=$ ratio of PMN AA:SAA. 
TABLE II

SAA Binding to Various Leukocyte Subpopulations

\begin{tabular}{lrlllll}
\hline & & \multicolumn{5}{c}{ In the pellet of: } \\
\cline { 3 - 7 } Subjects & SAA level & PMN & T lymphs & $\begin{array}{c}\text { B + null } \\
\text { lymphs }\end{array}$ & Monocytes & $\begin{array}{c}\text { Latex } \\
\text { particles }\end{array}$ \\
\hline & $n g / m l$ & & \multicolumn{5}{c}{$\% c p m$} \\
EP & 40 & 5.02 & 16.76 & 4.2 & 15.20 & 5.1 \\
MW & 875 & 4.8 & 13.5 & 7.07 & 14.1 & 4.8 \\
SP & 1,350 & 5.18 & 14.4 & 5.5 & 17.75 & 4.9 \\
JB & 2,500 & 4.59 & 15.54 & 3.7 & 13.85 & 4.7 \\
Mean & & 4.89 & 15.02 & 5.11 & 15.2 & 4.87 \\
\hline
\end{tabular}

The above percentage values represent the amount of $I^{125}$-SSA retained by various leukocyte subpopulations separated from the peripheral blood of a normal subject (EP) and of three patients with elevated SAA levels (MW, SP, $\mathrm{JB}$ ), as well as by control inert latex particles (diam 1.101 $\mu \mathrm{m}$, Dow Flow Corning Corp., Midland, Md.). $2 \times 10^{6}$ cells of each of the separated leukocyte subpopulations and $2 \times 10^{7}$ latex particles were incubated for $1 \mathrm{~h}$ at $37^{\circ} \mathrm{C}$ with $1-2 \mu \mathrm{l}$ of a $1 \mathrm{mg} / \mathrm{ml}$ solution of the radioactively labeled (21) pure SAA carrying $75,000 \mathrm{cpm}$. They were subsequently separated by centrifugation $(400 \mathrm{~g} \times 15 \mathrm{~min})$ from the supernatant medium, and their radioactivity was determined in a gamma counter.

and null lymphocytes. These results eliminate the possibility that the lack of SAA binding to granulocytes was a result of previous saturation of their receptor sites with circulating SAA, and ruled out SAA binding as a primary cause of the high intracellular content of AA antigenically related material by granulocytes.

Finally, when pure SAA was added to various leukocyte subpopulations before sonication, no significant degradation of SAA was detected by radioimmunoassay when the sonicated lysates were frozen within $15 \mathrm{~min}$ nor after they were thawed and kept at $37^{\circ} \mathrm{C}$ up to $2 \mathrm{hr}$. These conditions have been respected throughout the entire study; they eliminate the possibility that the low AA content of monocytes and lymphocytes was because of its more rapid degradation by these cells than by granulocytes.

Kinetics of SAA content of cultured leukocyte subpopulations and its release in the culture medium. AA antigenically related material was not present in the culture medium of $\mathrm{T}$ lymphocytes, $\mathrm{B}$ and null cells, or in the medium bathing the adherent monocytes. When it was found in the sonicated lysate of $T$ lymphocytes and monocytes, it was always in very small amounts $\left(<150 \mathrm{ng} / \mathrm{ml}\right.$ in $2 \times 10^{6}$ cells $)$; this level never increased in these cells when they were maintained in cultures for time intervals up to 7 days. In contrast, the PMN leukocytes maintained for up to $72 \mathrm{~h}$ in 199 , McCoy, or RPMI 1640 medium with $15 \%$ fetal calf serum, appeared to contain an increasing amount of AA antigenically related material starting in the 6 th $\mathrm{h}$ of incubation.
This increase reached a peak that varied for the eight individuals tested between the 16th and 30th $h$ and was followed by a subsequent fall in the level of AA antigenically related material that correlated well with the increasing percentage of nonviable leukocytes (Fig. 2). When the level of AA antigenic material was determined in the granulocyte culture media, two patterns were noted (Fig. 2). In the cultures of two patients with high SAA levels and high content of PMN AA, there was a moderate increase of the AA antigenically related material in the medium followed by a rapid fall that closely matched the variations of the AA content of the PMN leukocytes. In contrast, this increase in AA was not found in the media of PMN cultures from the other six cases studied.

The influence of protein synthesis inhibitors and antitubulin agents on the AA content of granulocytes was also analyzed; in the granulocyte cultures containing $0.1 \mu \mathrm{g} / \mathrm{ml}$ of puromycin or $10 \mu \mathrm{g} / \mathrm{ml}$ of cyclohexi-
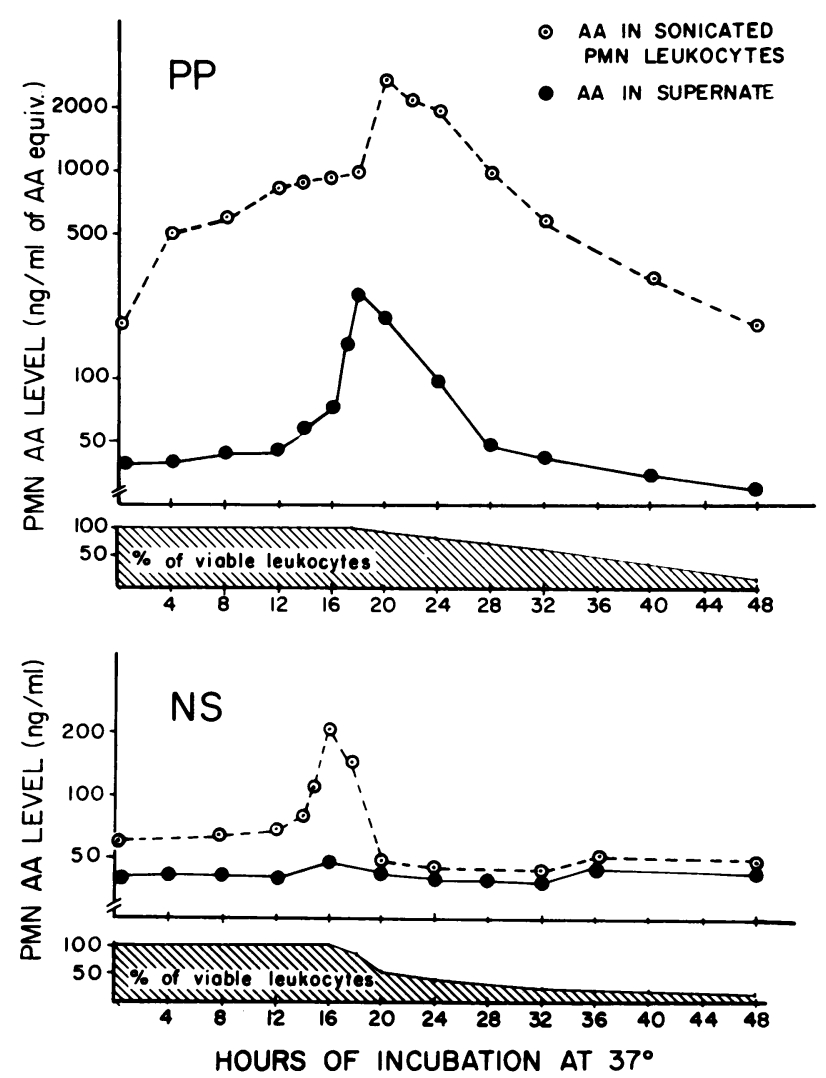

FIGURE 2 AA antigenically related material in PMN leukocytes in culture. $(-\odot---\odot-)=$ variations of AA content of sonicated PMN leukocytes over a 48-h period; (- - - - ) AA content of the culture medium. The upper graph represents the values for the leukocytes from one of the two cases whose PMN leukocytes appear to release the AA antigenically related material in the supernate. The lower graph is representative for the six cases whose PMN leukocytes did not release this substance in the supernate. 
mide, the expected increase of the intracellular AA antigenic material was inhibited by $40-80 \%$ between the 16th and 30th $\mathrm{h}$ of incubation (Table III). Vincristine and colchicine in concentrations between 2 and $200 \mathrm{ng} /$ $\mathrm{ml}$ blocked the release of AA from the granulocytes of the only two subjects in whom this release occurred spontaneously, but decreased by only $20-48 \%$ the intracellular AA content of PMN leukocytes in culture. Vinblastine did not have any significant influence on the AA level of the supernate or sonicated material.

\section{DISCUSSION}

The data presented above clearly indicate that PMN leukocytes are the only subpopulation of cells from the peripheral blood that contains a significant amount of AA antigenically related material. Although it is conceivable that this material could be phagocytized from the serum, the lack of binding of $\mathrm{I}^{125}$-SAA by these cells, the above described kinetic studies, and the inhibitory effect of puromycin and cycloheximide indirectly demonstrated that this AA antigenically related material is likely synthesized by the PMN leukocytes. As seen in two out of eight short-term granulocyte cultures, under certain conditions which remain to be defined better, this AA antigenically related material is released into the culture medium.

The kinetic studies also revealed that the events accompanying PMN leukocyte death lead to the degradation of PMN AA material (Fig. 2), or at least of a fragment with identical antigenicity as that of tissue AA and SAA, making it undetectable by radioimmunoassay when the percentage of dead granulocytes was $>50 \%$.

An active role of PMN leukocytes in the production of the AA precursor would be consistent with some observations made by us $(7,16)$ and others $(22)$ concerning a close correlation between the leukocyte count and the rise of the SAA level in patients with acute $(7,16)$ and some chronic (22) inflammatory processes as well as in those with chronic myelocytic leukemia (23). However, as we reported elsewhere (23), in many pathologic conditions (i.e., neoplastic diseases, acute myelocytic leukemia, rheumatoid arthritis, etc.) the increase of the SAA level was usually much higher than that of the PMN leukocyte count, suggesting either an absolute increase in the production of SAA by leukocytes or the existence of a supplemental source of SAA.

The inhibition of colchicine and vincristine of the occasional spontaneous release in vitro of the AA precursor from the PMN leukocytes (Table III) could

TABLE III

Effect of Protein Synthesis Inhibitors and Antitubulin Agents on the PMN AA Intracellular Level and on Its Release in the Culture Medium

\begin{tabular}{|c|c|c|c|c|c|c|c|c|c|c|}
\hline \multirow[b]{3}{*}{ Substances added to cultures } & \multicolumn{10}{|c|}{ PMN AA from eight granulocyte cultures identified by the donors' initials } \\
\hline & \multirow{2}{*}{$\begin{array}{l}\text { J. T. } \\
\text { (i.c. })^{*}\end{array}$} & \multirow{2}{*}{$\begin{array}{l}\text { R. O. } \\
\text { (i.c.) }\end{array}$} & \multirow{2}{*}{$\begin{array}{l}\text { D. K. } \\
\text { (i.c.) }\end{array}$} & \multirow{2}{*}{$\begin{array}{c}\text { A. } \mathbf{H} . \\
\text { (i.c.) }\end{array}$} & \multirow{2}{*}{$\begin{array}{l}\text { H. B. } \\
\text { (i.c.) }\end{array}$} & \multirow{2}{*}{$\begin{array}{l}\text { R. F. } \\
\text { (i.c.) }\end{array}$} & \multicolumn{2}{|c|}{ J. 0.} & \multicolumn{2}{|c|}{ P. P. } \\
\hline & & & & & & & i.c. & r.m.t & i.c. & r.m. \\
\hline & & & & & & $n g / m l$ & & & & \\
\hline None (control) & 290 & 600 & 508 & 895 & 515 & 193 & 280 & 175 & 2,020 & 320 \\
\hline Puromycin, $0.1 \mu \mathrm{g} / \mathrm{ml}$ & $\begin{array}{l}120 \\
(41)\end{array}$ & $\begin{array}{c}265 \\
(44)\end{array}$ & $\begin{array}{c}310 \\
(61)\end{array}$ & ND\$ & ND & $\begin{array}{r}<40 \\
\quad(21)\end{array}$ & $\begin{array}{l}105 \\
(37)\end{array}$ & $\begin{array}{r}<40 \\
(23)\end{array}$ & $\begin{array}{l}820 \\
(41)\end{array}$ & $\begin{array}{r}<40 \\
(12)\end{array}$ \\
\hline Cycloheximide, $10 \mu \mathrm{g} / \mathrm{ml}$ & $\begin{array}{l}110 \\
(38)\end{array}$ & $\begin{array}{c}90 \\
(15)\end{array}$ & $\begin{array}{c}216 \\
(42)\end{array}$ & ND & ND & $\begin{array}{c}82 \\
(42)\end{array}$ & $\begin{array}{c}55 \\
(20)\end{array}$ & $\begin{array}{c}40 \\
(23)\end{array}$ & $\begin{array}{c}650 \\
(32)\end{array}$ & $\begin{array}{r}<40 \\
(12)\end{array}$ \\
\hline Vincristine, $0.2 \mu \mathrm{g} / \mathrm{ml}$ & ND & ND & ND & $\begin{array}{l}470 \\
(52)\end{array}$ & $\begin{array}{l}410 \\
(80)\end{array}$ & $\begin{array}{l}167 \\
(86)\end{array}$ & $\begin{array}{c}177 \\
(63)\end{array}$ & $\begin{array}{c}55 \\
(31)\end{array}$ & $\begin{array}{r}1,550 \\
\quad(77)\end{array}$ & $\begin{array}{c}<40 \\
(12)\end{array}$ \\
\hline Colchicine, $0.2 \mu \mathrm{g} / \mathrm{ml}$ & ND & ND & $\begin{array}{c}415 \\
(82)\end{array}$ & $\begin{array}{l}450 \\
(50)\end{array}$ & $\begin{array}{c}215 \\
(42)\end{array}$ & $\begin{array}{l}156 \\
(81)\end{array}$ & $\begin{array}{l}103 \\
(37)\end{array}$ & $\begin{array}{c}40 \\
(23)\end{array}$ & $\begin{array}{r}1,525 \\
(75)\end{array}$ & $\begin{array}{c}55 \\
(17)\end{array}$ \\
\hline Vinblastine, $0.2 \mu \mathrm{g} / \mathrm{ml}$ & ND & ND & ND & $\begin{array}{r}1,075 \\
(120)\end{array}$ & $\begin{array}{c}605 \\
(117)\end{array}$ & $\begin{array}{l}175 \\
(91)\end{array}$ & $\begin{array}{l}211 \\
(75)\end{array}$ & $\begin{array}{l}125 \\
(71)\end{array}$ & $\begin{array}{r}1,900 \\
(94)\end{array}$ & $\begin{array}{c}280 \\
(87)\end{array}$ \\
\hline
\end{tabular}

The numbers in parentheses express the percentage of PMN AA found in the sonicated lysates (i.c.) or in the corresponding medium (r.m.) of cultures in which the agents indicated in the left column were added. The PMN AA values were determined at intervals corresponding to the time at which a maximum amount of PMN AA was found in the control culture. Each percentage was calculated from the amount in the respective control.

* i.c. = intracellular.

$\$$ r.m. $=$ released in medium.

$\S \mathrm{ND}=$ not determined. 
explain the previously reported blockade by colchicine of casein-induced amyloidosis in mice $(24,25)$. This observation could also explain the favorable results obtained with colchicine therapy in a few cases of Familial Mediterranean Fever with amyloidosis (26) and in some cases of primary amyloidosis (27).

The occasional presence of minimal amounts of AA antigenically related material in the $\mathrm{T}$ lymphocyte and monocyte subpopulations (Fig. 1) could have resulted from the binding of serum AA to their membranes or lysosomal particles. Contamination of the $B$ and null cell subpopulations and of the monocytes with occasional young PMN leukocytes could have also led to similar results for the respective cell subpopulations.

The foregoing observations do not preclude the existence of other tissue sites capable of synthesizing the precursor of AA protein and leave certain questions unanswered with regard to the synthesis and release of the AA precursor by PMN leukocytes. For example, In what conditions does it occur and what triggers it? Nevertheless, the present study clearly indicates that PMN leukocytes play a major role in the metabolism of this protein.

\section{ACKNOWLEDGMENTS}

We wish to thank Doctors E. C. Franklin and C. ZuckerFranklin for helpful advice, Dr. D. Galanakis for editorial help, and Ms. Linda Earle for secretarial assistance.

This work was supported by grants from the National Institutes of Health (IM01AM2008001) and the Mildred Werner League Foundation.

\section{REFERENCES}

1. Benditt, E. P., and N. Eriksen. 1966. Amyloid III. A protein related to the subunit structure of human amyloid fibrils. Proc. Natl. Acad. Sci. U. S. A. 55: 308-316.

2. Levin, M., M. Pras, and E. C. Franklin. 1973. Immunologic studies of the major non-immunoglobulin protein of amyloid. J. Exp. Med. 138: 373-380.

3. Husby, G., and J. B. Natvig. 1974. A serum component related to non-immunoglobulin amyloid AS, a possible precursor of the fibrils. J. Clin. Inv. 54: 1054-1061.

4. Anders, R. F., J. B. Natvig, T. E. Michaelsen, and G. Husby. 1975. Isolation and characterization of amyloidrelated serum protein SAA as a low molecular weight protein. Scand. J. Immunol. 4: 397-401.

5. Linke, R. P., J. D. Sipe, P. S. Pollock, T. F. Ignaczak, and G. G. Glenner. 1975. Isolation of a low molecular weight serum component antigenically related to an amyloid fibril protein of unknown origin. Proc. Natl. Acad. Sci. U. S. A. 72: 1473-1476.

6. Rosenthal, C. J., E. C. Franklin, B. Frangione, and J. Greenspan. 1976. Isolation and partial characterization of SAA - an amyloid related protein from human serum. J. Immunol. 116: 1415-1421.

7. Rosenthal, C. J., and E. C. Franklin. 1975. Variation with age and disease of an amyloid $A$ protein related serum component. J. Clin. Inv. 55: 746-753.
8. Benson, M. D., M. Skinner, J. Lian, and A. S. Cohen. 1975. "A" protein of amyloidosis. Arthritis Rheum. 18: 315-322.

9. Ignaczak, T. F., J. D. Sipe, R. P. Linke, and G. G. Glenner. 1977. Immunochemical studies on the nature of the serum component (SAA) related to secondary amyloidosis. $J$. Lab. Clin. Med. 89: 1092-1104.

10. Benson, M. D., M. A. Scheinberg, T. Shirahama, E. S. Cathcart, and M. Skinner. 1977. Kinetics of serum amyloid protein $A$ in casein-induced murine amyloidosis. J. Clin. Invest 59: 412-417.

11. Glenner, G. G., and D. L. Page. 1976. Amyloid, amyloidosis and amyloidogenesis. Int. Rev. Exp. Pathol. 15: 1-90.

12. Rosenthal, C. J., and E. C. Franklin. 1977. Amyloidosis and amyloid proteins. In Recent Advances in Clinical Immunology. R. A. Thompson, editor. Churchill Livingstone, Edinburgh, London, and New York. 1: 41-76.

13. Shirahama, T., and A. S. Cohen. 1975. Intralysosomal formation of amyloid fibrils. Am. J. Pathol. 81: 101-116.

14. Watanabe, S., E. Jaffe, S. Pollock, J. Sipe, and G. G. Glenner. 1977. Amyloid AA protein. Cellular distribution and appearance. Am. J. Clin. Pathol. 67: 540-544.

15. Linder, E., V. P. Lehto, I. Virtanen, S. Stenman, and J. B. Natvig. 1977. Localization of amyloid related serum protein SAA-like material to intermediate $(10 \mathrm{~nm})$ filaments of cultured human embryonal fibroblasts. J. Exp. Med. 146: 1158-1163.

16. Gorevic, P. D., C. J. Rosenthal, and E. C. Franklin. 1976. Amyloid-related serum component (SAA) - studies in acute infections, medullary thyroid carcinoma and postsurgery. Clin. Immunol. Immunopathol. 6: 83-93.

17. Scheinberg, M. A., and E. S. Cathcart. 1976. Casein induced experimental amyloidosis VI. A pathologic role for B cells in the murine model. Immunology 81: 443-452.

18. Boyum, A. 1968. Separation of leukocytes from blood and bone marrow. Scand. J. Clin. Lab. Invest. 21: (suppl.) $77-125$

19. Unanue, E. R., and J. M. Kiley. 1977. Synthesis and secretion of a mitogenic protein by macrophages: description of superinduction phenomenon. J. Immunol. 119: 925-931.

20. Yu, D. T. Y. 1975. Human lymphocyte subpopulations: early and late rosettes. J. Immunol. 115: 91-93.

21. Greenwood, F. C., W. M. Hunter, and J. J. Glover. 1963. The preparation of ${ }^{131}$-labelled human growth hormone of high specific radioactivity. Biochem. J. 89: 114-123.

22. McAdam, K. P. W. J., R. F. Anders, S. R. Smith, D. A. Russell, and M. A. Price. 1975. Association of amyloidosis with erythema nodosum leprosum reactions and recurrent neutrophil leucocytes in leprosy. Lancet. II: 572-576.

23. Rosenthal, C. J., and L. Sullivan. 1977. Serum amyloid A (SAA): immunosuppressing factor and monitor of metastatic spread of human neoplasia. Proceedings of the American Association for Cancer Research and the American Society of Clinical Oncology. 18: 212. (Abstract.)

24. Kedar, I., M. Ravid, E. Sohar, and J. Gafni. 1974. Colchicine inhibition of casein induced amyloidosis in mice. Isr. J. Med. Sci. 10: 787-789.

25. Shirahama, T., and A. S. Cohen. 1974. Blockage of amyloid induction by colchicine in an animal model. J. Exp. Med. 140: 1102-1107.

26. Goldfinger, S. E. 1972. Colchicine for Mediterranean fever. N. Engl. J. Med. 287: 1302-1306.

27. Ravid, M., M. Robson, and I. Kedar (Keizman). 1977. Prolonged colchicine treatment in four patients with amyloidosis. Ann. Intern. Med. 87: 568-570. 